OPEN ACCESS

Edited by:

Nancy W. Muturi,

Kansas State University, United States

Reviewed by:

Sakshi Bhati,

Kansas State University, United States

Thiago Teixeira Guimarães,

Air Force University, Brazil

*Correspondence:

Jin-Ae Kang

kangj@ecu.edu

Specialty section:

This article was submitted to Health Communication,

a section of the journal

Frontiers in Communication

Received: 03 December 2021

Accepted: 24 January 2022

Published: 21 February 2022

Citation:

Longest K and Kang J-A (2022) Social

Media, Social Support, and Mental

Health of Young Adults During

COVID-19.

Front. Commun. 7:828135

doi: $10.3389 /$ fcomm.2022.828135

\section{Social Media, Social Support, and Mental Health of Young Adults During COVID-19}

\author{
Kaitlyn Longest and Jin-Ae Kang* \\ School of Communication, East Carolina University, Greenville, NC, United States
}

The current study examines the impact of COVID-19 on the mental health among young adults in the US, how they use social media and the social support they obtain from the online environment, and the effect on their mental health during stay-at-home orders. Our survey among 18-to-25-year-olds found that women and those uncertain of employment status due to the pandemic experienced elevated depression symptoms. The informational acquisition motive for using social media was positively associated with depression symptoms, and a higher level of online informational support contributed to increasing the symptoms. Young adults showed the lowest level of depression symptoms when they had a higher level of offline emotional support and a lower level of online informational support. Our survey stressed the importance of offline emotional support and reconfirmed that nothing can replace its value.

Keywords: COVID-19, young adults, social media, emotional social support, online social support, depression

\section{INTRODUCTION}

In 2020, the COVID-19 pandemic created a quarantine culture in the US. The highly contagious virus caused the US to enforce stay-at-home orders. Young adults across the country were sent home from school, worked from home, and lost income and resources. Those governmental decisions were somewhat effective in flattening the curve of COVID-19 outbreaks in their early stage. However, the changes decreased the volume of face-to-face social interactions, and consequently, social support was absent from young adults' life during the pandemic. When social support is essential, especially as it is for a young adult's mental wellbeing and survival, how did young adults seek or offer social support in a physically isolated environment? Do social media contribute to sustaining social support for them? If so, is the social support available online the same as that in an offline context? Does online social support alleviate mental health problems? The current research attempted to answer those questions.

Previous studies demonstrate mixed perspectives on social media and the mental wellbeing of its users. Some show that social media provides social support and a sense of community for marginalized populations, who otherwise cannot find support groups in their offline network (e.g., Han et al., 2019). However, other studies describe alarming negative effects of social media on mental health. Critics note that social media force young adults to constantly compare their lifestyles and body shapes with others', causing deteriorating self-confidence and mental health problems (e.g., Vogel et al., 2014; Pasko and Arigo, 2021).

The current study contextualizes the contradictory claims of the effects of social media on mental health during the COVID-19 stay-at-home orders in the US. A study from China reports that 
excessive social media use during the COVID-19 lockdown situation caused unexpected mental health crises, such as depression and anxiety (Zhong et al., 2021). However, the study surveyed the adult residents in Wuhan, China, when the city was in the middle of lockdown. The implications there may not be valid in the US, because the mobility restriction was less strict, and participation was also voluntary. In the context of the current research, no study addresses how young adults, the digital-native generation, maintain social support and cope with mental health challenges using social media during the COVID19 outbreak. Understanding linkages among social media, social support, and mental health challenges would guide us toward better supporting young adults as we return to normalcy.

Therefore, our study addresses the issues between the pandemic and mental health among US young adults, to navigate the linkage between social media use and depression symptoms as a mental health outcome. Assuming that social media may be a resource for social support during a pandemic when restrictions apply to offline social interactions, our study explores the possible correlation between social support online and offline and levels of depression symptoms.

\section{LITERATURE REVIEW}

\section{The COVID-19 Pandemic and Mental Health}

COVID-19 is a highly contagious respiratory disease caused by a coronavirus called SARS-CoV-2, and symptoms vary from being mild, such as fatigue or headache, to severe illness and even death. Since the first confirmed case in the US was reported in Washington state on January 15, 2020, the virus spread rapidly throughout the country. In March 2020, nearly three out of four people were under stay-at-home orders or mandated quarantines, to reduce the rate of transmission (BBC News, 2020). As of May 2021, 33.1 million cases had been reported in the US, with 164 million confirmed cases worldwide, including 3.5 million deaths [WHO Coronavirus (COVID-19) Dashboard, 2021]. Such strong, aggressive measures altered the daily lives of many people, and many adults reported the pandemic's negative impact on their mental health (Panchal et al., 2021).

Public health emergencies such as natural disasters and massive accidents cause emotional distress among those who are affected by such crises (Pfefferbaum and North, 2020). Thus, the negative impact of the pandemic outbreak on mental health is not a new phenomenon. Being in quarantine due to potentially or actually contracting the disease, which may lead to work-life changes, infecting loved ones, and any other stressful event the virus could cause, increases symptoms of depression and anxiety (Rossi et al., 2020).

In the early stage of the pandemic, researchers paid attention to the mental health of specific populations, such as health care providers, essential workers, or residents living in lockdown areas, e.g., China or Italy (Greenberg et al., 2020; Rossi et al., 2020; Zhong et al., 2021). Two issues emerged from the research on the mental health effects of the pandemic. First, such studies are descriptive, reporting the mental health status of a particular group of people without addressing how the population copes with the pandemic situation, and how the coping methods can make a difference in their mental health. Second, mental health research must extend to other population segments, such as youth, young adults, ethnic minorities, or low-income families. Such subgroups would face unique mental distress in the situation and might need a different approach to cope. Thus, the current study focuses on young adults in the US, their mental health status, and their social media use as a coping method.

\section{Mental Health Among Young Adults During COVID-19 Pandemic}

Arguably, young adults are more vulnerable than others to the psychological effects of the COVID-19 pandemic. In the US, the mental health of young adults was a major public health concern even before the pandemic (Liu et al., 2019). However, the pandemic exacerbates the mental health issues of young adults in various ways. They have experienced disruption of college plans, family life, or employment (Perlis et al., 2021). Pew Research Center reports that young adults aged 18-29 exhibited higher levels of psychological distress than other age groups (Keeter, 2021). Another survey shows that $47.3 \%$ of participants aged $18-$ 24 experienced at least moderate depression symptoms (Perlis et al., 2021). In particular, the survey reports the correlations between depression symptoms and COVID-19 impact factors, such as starting to work from home, school or university closings, pay cuts due to reduced hours/demand for work, inability to make rent/mortgage payment, and being laid off or losing a job (Perlis et al., 2021). Such surveys effectively report adverse life consequences of COVID-19 on young adults' mental health. Thus, we developed the following hypotheses $1 \mathrm{a}$ and $1 \mathrm{~b}$.

H1: The scope of COVID-19 impact on (a) health and (b) life are positively associated with depression symptoms.

Meanwhile, several studies pay attention to the relationship between home confinement and higher rates of depression in young adults (Qi et al., 2020; Serafini et al., 2020), meaning that forced isolation relates to their mental wellbeing. However, the surveys mentioned do not address how young adults cope with home confinement situations and their effects on mental health. Maintaining social connections during the pandemic matters to young adults, and social media would be crucial for staying connected with the world, especially for young adults in physical isolation (e.g., Berryman et al., 2018).

\section{Social Media and Mental Health}

The mental health effects of social media on young adults have opened an ongoing debate with no consistent results. Contrasting viewpoints exist on the impact of time spent using social media on young adults' mental health. Some studies suggest an association between the two (e.g., Lin et al., 2016); other studies show that time spent using social media was unrelated to individual longitudinal changes in depression (e.g., Coyne et al., 2020). Such contrasting results may suggest that the simple calculation of time spent on social media use may or may not reveal the psychological mechanism behind it, such as motives for using social media for social support. 
Extant literature on Use and Gratification Theory research suggests two main motives for social media use: information acquisition and social interaction motives (Russo and Amnå, 2016). The information acquisition motive illustrates the information-seeking behaviors of those who visit different social media platforms to find the information they need. The social interaction motive explains communication-related activities that motivate people to maintain and expand their social circle, by engaging in social activities on social media. During the COVID-19 stay-at-home orders, such motives would predictably increase young adults' use of social media. In the public health crisis, people are eager to search for more information about the disease and preventative measures. Forced isolation increases the need for social interaction online, but this does not yet fully address how such motives are linked to mental health among young adults.

Zhong et al.'s (2021) research reports the ambivalent impact of social media use on mental health. Their study found social media usage beneficial because it kept survey participants informed on current health information and connected with their peers when the government lockdown order strongly discouraged or prohibited face-to-face interactions. However, increased perception of social media as a source of informational and emotional support increased time spent on social media and resulted in an increase of depression symptoms among Wuhan residents. The study by Zhong et al. (2021) examines the direct association between mental health issues and time spent on social media use during the pandemic. However, the study actually reveals the influence on depression of motives for using social media or social supports. Also, the association between time spent on social media use and mental health must be tested again among young adults in the US, due to previous mixed findings. Therefore, we develop the following hypotheses.

$\mathrm{H} 2 \mathrm{a}$ : There is an association between the information acquisition motive for social media use and depression symptoms.

$\mathrm{H} 2 \mathrm{~b}$ : There is an association between the interpersonal interaction motive for social media use and depression symptoms.

$\mathrm{H} 2 \mathrm{c}$ : The amount of time spent on social media is associated with depression symptoms.

\section{Social Support and Mental Health}

Social support is a perception of mechanisms in which one has assistance available from other people from his or her supportive social network, such as family, friends, or coworkers (Cobb, 1976; Cohen and McKay, 1984; House, 1986). The resources include emotional (e.g., validation of one's feelings), informational (e.g., advice), companionship (e.g., sense of belonging), or instrumental aid (e.g., financial assistance). Social support plays an important role in an individual's mental health; each component of social support functions as a bumper that protects individuals from stressors and maintains mental wellbeing.

Many studies from numerous disciplines explore the functional components of social support mentioned above.
Three functions of social support stand out from communication perspectives: informational, positive social interaction, and emotional support (Leung and Lee, 2005; Naslund et al., 2016; Selkie et al., 2020). First, information support offers guidance, advice, information, or feedback that can provide a solution to a problem (Leung and Lee, 2005). Interpersonal support refers to a positive social interaction that involves spending time with others in their leisure time (Sherbourne and Stewart, 1991). Such peer support also occurs when individuals offer the results of experience to help one another. Last, emotional support includes providing love, acceptance, caring, and encouragement.

Although social support benefits mental wellbeing at all ages, the extant literature validates its positive impact on the mental wellbeing of young adults. For example, Bovier et al. (2004) note that social support buffers the negative impact of stress on mental health by increasing college students' self-esteem and mastery of their lives. Another study reports that when college students who experience a traumatic event receive more support from friends and cope with the symptoms in an interpersonal style, they report less severe PTSD symptoms (Haden et al., 2007).

\section{Online Social Support and Mental Health}

Scholars have observed social support in an online environment through social networks. For instance, people support their peers by forwarding or sharing online news that would benefit friends online. Public officials update citizens through social media account updates in such situations as natural disasters, crime, or accidents. People obtain interpersonal support (peer support) through interacting with like-minded individuals on social media platforms (Naslund et al., 2016). These three types of support play an essential role in decreasing the number of depressive symptoms an individual feels. Emotional support is evident in an online support group of cancer patients and their families. An online group not only shares information, such as doctors or treatments but also encourages each member and shows emotional support for patients and families, providing a sense of community and lessening the feeling of desperation. The motivations and supports stand out, especially among those who have particular needs, such as patients with cancer or mental illness, or gender minority groups (Beaudoin and Tao, 2007; Han et al., 2019).

However, extant literature also documents the negative impacts of online social support on mental health. For example, the study by Brailovskaia et al. (2020) found that participants with perceived online social support often experienced Facebook Addiction Disorder (FAD), which ultimately hurts both mental and physical health. Shensa et al. (2016) found that emotional support obtained from social media differs from face-to-face emotional support that decreases the risk of depression in young adults; social-media-oriented emotional support increases the risk of depression (Shensa et al., 2020).

\section{Online Social Support, Mental Health, and COVID-19}

The role of online social support becomes crucial to increasing the likelihood of reducing psychological distress during the outbreak of COVID-19. The negative psychological impact of quarantine or lockdown during the COVID-19 has been studied 
extensively (e.g., Serafini et al., 2020). Fewer studies explore social support as a protective factor. For instance, Qi et al. (2020) found a lower prevalence of mental health problems among adolescents with high levels of social support during the COVID-19 outbreak. Lee and You's (2020) survey found an association between a stronger significant perception of social support and a reduced likelihood of developing psychological distress. Social support in both studies refers to an offline context.

There is little research on the impact of online social support on mental health in the COVID-19 pandemic. Zhong et al. (2021) found that the more people perceive social support online, the more likely they are to use social media and develop depression symptoms. However, their studies address online social support only in a forced lockdown situation in Wuhan, China, where only online social support was available. Both online and offline social support is available in normal life, even in a stay-home order situation. Studies have still not fully addressed how most people utilize their offline and online social support to cope with a quarantine situation. How the specific dimensions of informational, interpersonal, and emotional social support online and offline help people to deal with such a stressful event in their lives is an important issue that deserves further attention. Therefore, we developed the following hypotheses and one research question:

H3: (a) Informational, (b) interpersonal, and (c) emotional social support online are negatively associated with depression symptoms.

H4: (a) Informational, (b) interpersonal, and (d) emotional social support offline are negatively associated with depression symptoms.

RQ1: How do online and offline social support interact to impact depression symptoms?

\section{METHODS}

\section{Online Survey}

We adopted an online survey to address our hypotheses and research question. We used Qualtrics to transmit the online survey and recruited (using small incentives) research participants from Amazon's Mechanical Turk (MTurk) and a large public university in a southeastern state in December 2020 through January 2021.

We recruited research participants in the following 11 states: California, Connecticut, Delaware, Massachusetts, New Jersey, New York, North Carolina, Pennsylvania, Rhode Island, Virginia, and Washington. Those states used relatively strict measures regarding stay-at-home orders, mask mandates, travel restrictions, and COVID-19 cases from March through May 2020 (Nace, 2020; National Academy for State Health Policy, 2020). Since our research focus is on the COVID-19 impact on young adults' mental wellbeing, the survey targeted young adults aged 18 to 25 .

At the beginning of the survey, survey participants were asked their age, and which state they had been during the March and May 2020. If a respondent did not live in the listed states above during March and May 2020 or older than 25, then they were screened out from the survey. Survey participants saw informed consent forms at the beginning of the online survey. On average, participants spent 9.84 min completing the survey.

\section{Sample}

A total of 509 participants were recruited in December 2020, of whom 177 participated through Amazon mTurk and 332 from the university. We conducted a two-sample independent $T$-test regarding all items the survey measured, to test the homogeneity of the dataset collected via two different routes. The results showed no statistically significant differences in the averages for all variables. The average age range was 22.5 years old $(\mathrm{SD}=$ 2.29). The average education level was a 4 -year college degree $(\mathrm{SD}=0.92)$, and $72.4 \%(n=435)$ of the sample self-identified as Caucasian.

\section{Measures \\ Depression Symptoms}

Depression symptoms measurement was adopted from Lewinsohn et al.'s (1997) study that developed the depression scale (CES-D). Twenty items were measured with four-point Likert scales, ranging from 1 (Rarely) to 4 (most or all the time): Cronbach $\alpha=0.904$.

\section{COVID-19 Impact on Health}

For the health impact of COVID-19, we asked five questions with a dichotomous format as follows: (a) I have been tested positive for COVID-19, (b) My family has been tested positive for COVID-19, (c) My close friends have been tested positive for COVID-19, (d) I have close friends or family who were hospitalized due to COVID-19, and (e) I had friends or family members who lost their lives due to COVID-19. If the question was answered yes, it was counted as 1. Thus, we computed the scope of COVID-19 impact on health, which ranges from 0 to $5(\mathrm{M}=1.91, \mathrm{SD}=1.66)$.

\section{COVID-19 Impact on Life}

The impact of COVID-19 on life is defined as the scope of impact of COVID-19 on non-health-related areas in general. Eleven statements were adopted from Perlis et al.'s (2021) report of a 50 state COVID-19 survey. Several items among the 11 statements include (a) started working from home, (b) school or university closed, (c) stopped/reduced work to take care of someone with COVID-19, (d) pay cut due to reduced hours/demand for work, (e) collected unemployment benefits, and (f) laid off/furlough/lost a job, among others. Survey participants were asked to answer yes (coded as 1) or no (coded as 0 ) on each statement. The scope of the COVID-19 impact on life was calculated by adding all the coded scores. Thus, the scope ranges from 0 to $11(\mathrm{M}=4.92, \mathrm{SD}=3.04)$.

\section{Informational Acquisition Motive of Social Media Use}

Five items of information acquisition motivation of social media use were adopted from Gil de Zúñiga et al.s (2012) study and edited accordingly for our study: Social media is useful to (a) get COVID-19 related news from mainstream news, (b) to get COVID-19 related news through friends, (c) to stay informed about COVID-19 related local news, (d) to stay 
informed about the local community issues during the stay-athome order, and (e) to stay informed about current events and public affairs during the stay-at-home order on a Likert scale ranging from 1 (strongly disagree) to 5 (strongly agree): $\mathrm{M}=$ $3.47, \mathrm{SD}=0.97 ; \alpha=0.884$.

\section{Interpersonal Motive of Social Media Use}

We adopted six items for the interpersonal communication motive of social media use (Wang et al., 2019): During staying at home from the last March through May 2020, Social media is useful (a) To stay connected with friends and colleagues who I do not see due to the stay-home order, (b) To stay connected with friends and colleagues whom I want to catch up with, (c) To meet new people, (d) To improve my interpersonal relationship, (e) To find friends and colleagues who share the same interests as mine, and (f) to organize or participate in various social activities on a Likert scale ranging from 1 (strongly disagree) to 5 (strongly agree): $\mathrm{M}=3.58, \mathrm{SD}=0.79 ; \alpha=0.806$.

\section{Time Spent on Social Media During the Stay-at-Home Order}

We also asked how many hours the survey participants used in social media during the stay-at-home order from March to May. Answer options range from (a) $<10 \mathrm{~min}$, (b) 10-30 min, (c) 30$60 \mathrm{~min},(\mathrm{~d}) 1-2 \mathrm{~h},(\mathrm{e}) 2-3 \mathrm{~h}$, and (f) more than $3 \mathrm{~h}$. The median was $1-2 \mathrm{~h}$.

\section{Social Support}

We adopted social support measurement from Leung and Lee (2005) study, which has three sub-dimensions of social support: Informational support (4 items), interpersonal support (3 items), and emotional support (4 items). Selected items include: When I was not on the internet/social media, there was: (a) someone whose advice I really want, (b) someone to give me good advice about a crisis, (c) someone to get together with for relaxation and (d) someone who comforts me sincerely among others. The items were asked again at the social meeting setting. Thus, each set of 11 items were asked to measure online social support and offline social support, respectively: Online social support: $\mathrm{M}=3.25 \mathrm{SD}$ $=0.86$, Cronbach $\alpha=0.923$; Offline social support: $\mathrm{M}=3.32, \mathrm{SD}$ $=0.90$, Cronbach $\alpha=0.938$.

\section{Covariates}

Data such as age, gender, education level, and whom they live with and work status during the stay home order were controlled during the statistical analysis. Correlation of the key variables are presented in the Table $\mathbf{1}$.

\section{RESULTS}

We used a hierarchical regression analysis to test the hypotheses. Hierarchical regression is useful when variables of a researcher's interest explain significant amount of variance in the outcome variable after accounting for all other variables. We built five models in the analysis, and each model addresses the impact of covariates, COVID-19 impact, motives of social media use, online social support and offline social support on depression symptoms.

Hypothesis $1 \mathrm{a}$ and $1 \mathrm{~b}$ address the impact of COVID-19 on depression. The regression results show that the COVID19 impact on health is positively associated with depression symptoms (Table 2: $\beta=0.14, p<0.01$ ). The more COVID-19 affected aspects of the respondents' lives, the more likely they were to feel depressed $(\beta=-0.13, p<0.001)$. Thus, our data confirm H1a and H1b.

$\mathrm{H} 2$ examined the association between social media usage and depression symptoms during the stay-at-home-order period. The results show that an information-acquisition motive is positively associated with depression symptoms (Table 2: H2a: $\beta=0.16$, $p<0.01$ ), while the motivation for interpersonal interaction on social media (H2b) was not associated with depression symptoms at a statistically significant level. We expected the amount of time used on social media would be positively associated with depression symptoms. However, our data did not confirm $\mathrm{H} 2 \mathrm{c}$, addressing the association between the time on social media and depression during the stay-home order. In sum, our data confirmed $\mathrm{H} 2 \mathrm{a}$, but not $\mathrm{H} 2 \mathrm{~b}$ and $\mathrm{H} 2 \mathrm{c}$.

$\mathrm{H} 3$ and $\mathrm{H} 4$ address the impact on depression symptoms of online and offline social support, respectively. The regression analysis demonstrated that online informational support had a positive association with depression (Table 2: $\beta=0.14, p<0.05$ ). Regarding offline social support, emotional support showed a negative association with depression, indicating positive mental wellbeing. Thus, our data confirmed only $\mathrm{H} 3 \mathrm{a}$ and $\mathrm{H} 4 \mathrm{c}$, and all other subdimensions of social support were found not associated with depression symptoms.

To answer research question 1 , we explored the interaction effects of online and offline social support regarding depression symptoms. The first two-way analysis of covariance (ANCOVA) was conducted considering social support as a one-dimensional construct. The tests of the between-subjects effect show an interaction effect between online and offline social support, but the $p$-value is slightly higher than 0.05 [Figure 1: $F_{(1,486)}=$ 3.605, $\left.p=0.058, \eta^{2}=0.007\right]$. The depression symptoms are at the lowest level when the respondents have high levels of offline social support and low levels of online social support (Figure 1; $M=2.09$ ). However, the depression level goes up when the respondents perceive that they got support online, although they still have a high level of offline social support $(M=$ 2.34). When the responses show lower social support offline, the online social support level does not change depression symptoms much $(\mathrm{M}=2.40$ vs. $\mathrm{M}=2.44)$. However, the depression level is higher than those who show high social support both online and offline $(M=2.34)$. The depression level was highest when the respondents had low offline social support and high online social support $(\mathrm{M}=2.44)$.

We also tested the interaction effect between informational social support online and emotional social support offline, since the findings from the hypotheses testing suggest those social support are associated with depression symptoms. The tests of between-subjects effects show an interaction effect at a statistically significant level [Figure 1: $F_{(1,486)}=7.744, p=$ $\left.0.006, \eta^{2}=0.016\right]$. We found that depression symptoms were 
TABLE 1 | Correlation of key variables.

\begin{tabular}{|c|c|c|c|c|c|c|c|c|c|c|c|c|c|c|c|c|c|}
\hline & 1 & 2 & 3 & 4 & 5 & 6 & 7 & 8 & 9 & 10 & 11 & 12 & 13 & 14 & 15 & 16 & 17 \\
\hline 1. Depression & 1 & & & & & & & & & & & & & & & & \\
\hline 2. Age & 0.028 & 1 & & & & & & & & & & & & & & & \\
\hline 3. Gender & -0.060 & $0.157^{\star \star}$ & 1 & & & & & & & & & & & & & & \\
\hline 4. Education & 0.080 & $0.443^{\star \star}$ & $0.148^{\star \star}$ & 1 & & & & & & & & & & & & & \\
\hline 5. Living with someone ${ }^{+}$ & 0.083 & -0.053 & 0.018 & 0.009 & 1 & & & & & & & & & & & & \\
\hline 6. COVID-19 health impact & $0.271^{\star \star}$ & 0.055 & 0.073 & $0.201^{\star *}$ & $0.200^{\star \star}$ & 1 & & & & & & & & & & & \\
\hline 7. COVID-19 life impact & $0.315^{\star \star}$ & $0.242^{* \star}$ & $0.190^{\star \star}$ & $0.317^{\star \star}$ & $0.120^{\star \star}$ & $0.545^{\star \star}$ & 1 & & & & & & & & & & \\
\hline 8. Work status insecurity^ & 0.033 & $-0.356^{\star \star}$ & -0.038 & $-0.361^{\star \star}$ & 0.020 & $-0.142^{\star \star}$ & $-0.297^{\star \star}$ & 1 & & & & & & & & & \\
\hline $\begin{array}{l}\text { 9. Information acquisition motive of } \\
\text { social media use }\end{array}$ & $0.242^{* *}$ & $0.140^{\star \star}$ & 0.027 & $0.162^{\star \star}$ & $0.148^{\star \star}$ & $0.250^{\star *}$ & $0.336^{* \star}$ & $-0.178^{\star \star}$ & 1 & & & & & & & & \\
\hline $\begin{array}{l}\text { 10. Interpersonal motive of social } \\
\text { media use }\end{array}$ & $0.165^{\star \star}$ & 0.083 & 0.004 & $0.146^{\star \star}$ & 0.057 & $0.322^{\star \star}$ & $0.332^{\star \star}$ & $-0.104^{\star}$ & $0.477^{\star \star}$ & 1 & & & & & & & \\
\hline $\begin{array}{l}\text { 11. Hours per day on social media } \\
\text { use }\end{array}$ & 0.004 & $-0.214^{\star \star}$ & $-0.239^{\star \star}$ & $-0.176^{\star \star}$ & 0.004 & -0.077 & $-0.220^{\star \star}$ & $0.205^{\star \star}$ & 0.052 & $0.099^{\star}$ & 1 & & & & & & \\
\hline $\begin{array}{l}\text { 12. Online informational social } \\
\text { support }\end{array}$ & $0.207^{\star \star}$ & $0.180^{* *}$ & 0.042 & $0.231^{\star *}$ & $0.089^{*}$ & $0.284^{* \star}$ & $0.310^{\star *}$ & $-0.139^{\star \star}$ & $0.528^{\star \star}$ & $0.513^{\star \star}$ & 0.009 & 1 & & & & & \\
\hline $\begin{array}{l}\text { 13. Online interpersonal social } \\
\text { support }\end{array}$ & $0.096^{*}$ & $0.102^{*}$ & 0.015 & $0.107^{\star}$ & 0.052 & $0.191^{* *}$ & $0.217^{\star *}$ & -0.069 & $0.344^{\star \star}$ & $0.528^{\star \star}$ & $0.101^{*}$ & $0.578^{\star \star}$ & 1 & & & & \\
\hline 14. Online emotional social support & $0.141^{\star *}$ & $0.128^{\star *}$ & -0.039 & $0.133^{\star \star}$ & 0.057 & $0.258^{\star \star}$ & $0.268^{\star \star}$ & -0.072 & $0.333^{\star \star}$ & $0.479^{\star *}$ & 0.008 & $0.633^{\star \star}$ & $0.666^{\star \star}$ & 1 & & & \\
\hline $\begin{array}{l}\text { 15. Offline informational social } \\
\text { support }\end{array}$ & -0.052 & $0.166^{\star \star}$ & 0.009 & $0.179^{* \star}$ & 0.069 & $0.204^{\star \star}$ & $0.209^{* \star}$ & -0.041 & $0.263^{\star \star}$ & $0.294^{\star \star}$ & -0.055 & $0.540^{\star *}$ & $0.364^{\star \star}$ & $0.455^{\star \star}$ & 1 & & \\
\hline $\begin{array}{l}\text { 16. Offline interpersonal social } \\
\text { support }\end{array}$ & $-0.100^{\star}$ & 0.078 & -0.041 & 0.081 & $0.130^{* \star}$ & $0.146^{\star \star}$ & $0.124^{\star \star}$ & -0.001 & $0.197^{\star \star}$ & $0.221^{\star \star}$ & 0.003 & $0.335^{\star \star}$ & $0.428^{\star \star}$ & $0.383^{\star *}$ & $0.671^{\star \star}$ & 1 & \\
\hline 17. Offline emotional social support & $-0.109^{\star}$ & $0.108^{\star}$ & -0.055 & 0.087 & $0.102^{\star}$ & $0.153^{\star \star}$ & $0.131^{\star \star}$ & 0.003 & $0.156^{\star \star}$ & $0.172^{\star \star}$ & -0.084 & $0.325^{\star \star}$ & $0.308^{\star \star}$ & $0.452^{\star \star}$ & $0.658^{\star \star}$ & $0.739^{\star \star}$ & 1 \\
\hline
\end{tabular}

${ }^{*} p<0.05,{ }^{* *} p<0.01 ;+$ Living with someone: $0=$ live alone, 1 = live with friends, partner, or family; ${ }^{*}$ Work Status Insecurity: 1 = work remotely; $2=$ work onsite; $3=$ unemployed. 
TABLE 2 | Hierarchical regression of depression during stay-at-home order.

\begin{tabular}{|c|c|c|c|c|c|c|c|c|c|c|c|c|c|c|c|}
\hline & \multicolumn{3}{|c|}{ Model 1} & \multicolumn{3}{|c|}{ Model 2} & \multicolumn{3}{|c|}{ Model 3} & \multicolumn{3}{|c|}{ Model 4} & \multicolumn{3}{|c|}{ Model 5} \\
\hline & B & $\beta$ & SE & B & $\beta$ & SE & B & $\beta$ & SE & B & $\beta$ & SE & B & $\beta$ & SE \\
\hline Age & 0.00 & 0.01 & 0.01 & 0.00 & 0.01 & 0.01 & 0.00 & 0.00 & 0.01 & 0.00 & 0.00 & 0.01 & 0.01 & 0.02 & 0.01 \\
\hline Gender $(0=$ female, $1=$ male $)$ & -0.09 & -0.08 & 0.05 & -0.15 & $-0.13^{\star \star}$ & 0.05 & -0.15 & $-0.12^{\star *}$ & 0.05 & -0.15 & $-0.13^{\star \star}$ & 0.05 & -0.17 & $-0.14^{\star \star}$ & 0.05 \\
\hline Education & 0.07 & $0.10^{*}$ & 0.03 & 0.03 & 0.04 & 0.03 & 0.03 & 0.04 & 0.03 & 0.02 & 0.03 & 0.03 & 0.02 & 0.04 & 0.03 \\
\hline Living with someone & 0.14 & $0.08+$ & 0.08 & 0.02 & 0.01 & 0.08 & -0.01 & -0.01 & 0.08 & -0.01 & -0.01 & 0.08 & 0.02 & 0.01 & 0.08 \\
\hline COVID-19 health impact & & & & 0.05 & $0.14^{\star \star}$ & 0.02 & 0.05 & $0.14^{\star \star}$ & 0.02 & 0.05 & $0.13^{\star}$ & 0.02 & 0.05 & $0.14^{\star \star}$ & 0.02 \\
\hline COVID-19 life impact & & & & 0.11 & $0.30^{\star \star \star}$ & 0.02 & 0.10 & $0.27^{\star \star \star}$ & 0.02 & 0.10 & $0.27^{\star \star \star}$ & 0.02 & 0.10 & $0.26^{\star \star \star}$ & 0.02 \\
\hline Work status insecurity^ & & & & 0.11 & $0.15^{\star \star}$ & 0.03 & 0.12 & 0.17 & 0.03 & 0.12 & $0.16^{\star \star}$ & 0.03 & 0.14 & $0.19^{\star \star \star}$ & 0.03 \\
\hline $\begin{array}{l}\text { Information acquisition motive of } \\
\text { social media use }\end{array}$ & & & & & & & 0.10 & $0.16^{\star \star}$ & 0.03 & 0.08 & $0.13^{\star}$ & 0.03 & 0.08 & $0.13^{*}$ & 0.03 \\
\hline $\begin{array}{l}\text { Interpersonal motive of social media } \\
\text { use }\end{array}$ & & & & & & & -0.03 & -0.04 & 0.04 & -0.03 & -0.03 & 0.04 & -0.04 & -0.05 & 0.04 \\
\hline Hours per day on social media use & & & & & & & 0.00 & 0.00 & 0.02 & 0.00 & 0.00 & 0.02 & -0.01 & -0.02 & 0.02 \\
\hline Online informational SS & & & & & & & & & & 0.08 & $0.14^{\star}$ & 0.04 & 0.12 & $0.19^{\star \star}$ & 0.04 \\
\hline Online interpersonal SS & & & & & & & & & & -0.05 & -0.08 & 0.04 & -0.03 & -0.05 & 0.04 \\
\hline Online emotional SS & & & & & & & & & & -0.01 & -0.03 & 0.03 & 0.04 & 0.06 & 0.04 \\
\hline Offline informational SS & & & & & & & & & & & & & -0.08 & $-0.12+$ & 0.04 \\
\hline Offline interpersonal SS & & & & & & & & & & & & & -0.03 & -0.06 & 0.04 \\
\hline Offline emotional SS & & & & & & & & & & & & & $-0.08^{\star}$ & -0.14 & 0.04 \\
\hline $\mathrm{R}^{2}$ & & $0.020^{*}$ & & & 0.154 & & & 0.173 & & & 0.182 & & & 0.237 & \\
\hline$\Delta \mathrm{R}^{2}$ & & $0.020^{*}$ & & & $0.133^{\star \star \star}$ & & & $0.019^{\star \star}$ & & & 0.009 & & & $0.055^{\star \star \star}$ & \\
\hline
\end{tabular}

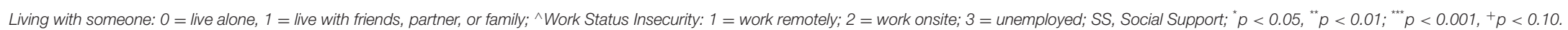




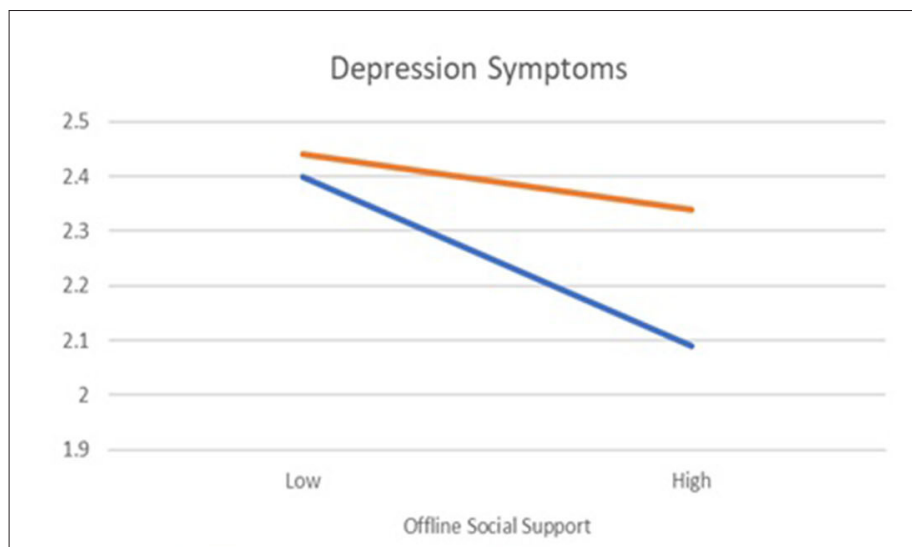

-Online Social Support Low -Online Social Support High

\section{Depression Symptoms}

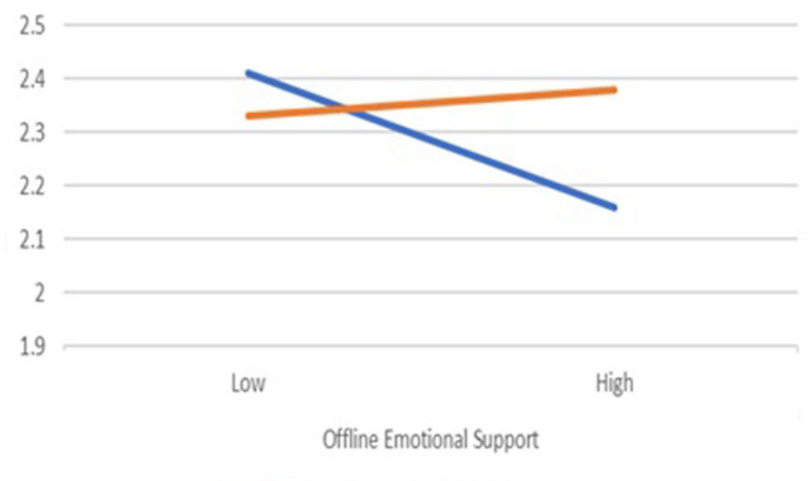

-Online Informational Social Support Low

Online Informational Social Support High

FIGURE 1 | Interaction effect between online and offline social support on depression symptoms.

lowest when the respondents get a high level of offline emotional support and a low level of online informational support (M $=2.16$ ). Although the respondents have high offline emotional support, the depression level increased when they perceived high information support online $(M=2.38)$. Depressional symptoms presented at the highest level when respondents had a low level of offline emotional support and a high level of online informational support $(M=2.41)$. Depression level decreased as the respondents received informational support $(M=2.33)$, but the difference is not as big as the gap between 2.16 and 2.38 (the graph on the right side of Figure 1).

\section{DISCUSSION}

The current study addresses the impact of COVID-19 on the mental health of the US young adults and how they use social media to keep social support and cope with stress caused by the pandemic. Social media has been regarded as a potential tool for enhancing social support for those who cannot locate adequate social support groups offline (Beaudoin and Tao, 2007; Naslund et al., 2016; Han et al., 2019). Thus, it was expected that social media would play a crucial role in young adults dealing with mental health issues during the pandemic. Our study demonstrates several noteworthy implications regarding the impact of social media use on young adults' mental health during the COVID-19 pandemic.

First, the current study adds to the extant literature's empirical evidence of the impact of COVID-19 on young adults' psychological distress. As we easily anticipated, the survey participants reported depressive symptoms accompanying their family and friends being exposed to or contracting the virus or contracting the virus themselves (H1a). The life impact of the COVID-19 pandemic and the stay-at-home orders was significant enough to increase the rates of depression symptoms among young adults ( $\mathrm{H} 1 \mathrm{~b})$. Online schooling, working from home, and isolation contributed to the depressive symptoms. In particular, the work status change-unemployment or losing income that the pandemic caused-emerged as the main stressor (H1d), and women seemed to be more depressive than men (Table 1: $\beta=-0.14, p<0.05$ ). Extant literature already documents women as generally more vulnerable to mental health issues than males, and the COVID-19 situation was no exception. The recovery programs that focus on female young adults are necessary.

Second, our study demonstrates the amount of time spent on social media use was not associated with depression symptoms. Young adults in their early 20 s are digital natives. For them, social media is an indispensable tool that connects them to the world, regardless of the pandemic outbreak. Therefore, the key issue is not how long social media is used, but how social media is used. The results of testing $\mathrm{H} 2 \mathrm{a}$ show that the motives of acquiring COVID-19 information relate to mental health problems. Negative news stories surrounded young adults, about the rising case numbers, extended stay-at-home orders, climbing death toll from the virus, and other politicized pandemicrelated news not only from March through May 2020 but also throughout 2020. The combination of all these elements made information-seeking on social media a negative experience for young adults.

The results of testing $\mathrm{H} 2 \mathrm{a}$ and $\mathrm{H} 3 \mathrm{a}$ raise a question regarding the reason why the motivation to seek information and online informational support does not contribute to mental wellbeing. Although our study does not aim to address the underlying mechanism behind the negative association between social media use and mental health, the extant literature on information overload and perceived mastery of life enhance our understanding of the relationship between social media use and mental health.

Information overload occurs when an individual must process an amount of information that exceeds his or her processing 
capability (Chen et al., 2009). During the COVID-19 pandemic, people extensively used social media to access health information (Mertens et al., 2020), often exposing them to information that exceeded their ability to digest it. Such overloads often trigger negative consequences, such as social media discontinuance or psychological shutdown (e.g., Henriques and Panizo, 2018; Liu et al., 2021). Reducing the incoming volume of information itself is not harmful. However, the feeling of being overwhelmed or experiencing a psychological shutdown might cause the loss of perceived mastery of life. Mastery refers to "the extent to which one regards one's life-chances as being under one's own control in contrast to being fatalistically ruled" (Pearlin and Schooler, 1978, p. 5). People actively seek information to navigate the pandemic situation. However, early 2020 was the period when reports on outbreaks of positive cases or symptoms were available, not cures or vaccine development. Therefore, the failure to process an enormous amount of information and the feeling of helplessness to overcome the pandemic environment could cause deterioration of the mental health of young adults.

Last, this study provides communicative implications to those who want to help young adults toward the post-COVID mental health recovery, e.g., college leadership, employers, non-profit organizations, families, and friends. Lives returning to normalcy require a careful effort to rebuild offline social support. Our study emphasizes that emotional support from offline relations is critical to reducing depressive symptoms. Having someone who shows love and listens to someone in person would make a difference. Also, not being overwhelmed with seeking too much information from relationships that exist mainly online (RQ1) is key. The use of social media would interfere with their faceto-face emotional support and promote greater social isolation (Shensa et al., 2016, 2020).

One noteworthy finding is that offline informational support could possibly be associated with reducing depression symptoms, although the statistical finding is slightly beyond the conventional level (see Table 2). Offline information support, such as giving good advice about a crisis or seeking suggestions about how to deal with a personal problem, is likely to come from those who show emotional and affective support through care and love. In other words, offline informational support would work best when based on affective support. Online informational support is unlikely to have the deeper caring of offline information support. Therefore, people returning to normalcy and rebuilding offline social support must nurture emotional support first, not rush to facilitate mere in-person social interactions or information forwarding.

Our finding regarding the importance of offline support provides an implication to mental health professionals. Young adults with depression could receive better treatment when the healthcare professionals involve the patient's support group such as friends and family into the care process. Future mental health intervention research could be developed from this point.

In sum, nothing can completely replace offline life and connection. Online social support was not found to enhance young adults' mental wellbeing and cannot serve as an adequate long-term substitute for offline social support that is essential for mental wellness among young adults. Such results contribute to the open and ongoing debate about the effects of social media on young adults' mental health. Our research adds evidence to the negative impact of social media on mental health.

\section{LIMITATIONS AND SUGGESTIONS FOR FUTURE STUDIES}

There are several limitations of our study that future studies must address. First, participants were asked in December 2020 and January 2021 to recall their experiences of March 2020. The participants' recollections from the March stay-at-home orders in 2020 may not have been identical to their feelings at the time. Second, most of our survey respondents self-identified as Caucasian. When the life impact of COVID-19 on other racial minorities is harder than that on Caucasians, our results would not reflect the reality of COVID-19 impact on such diverse populations. Future studies must particularly focus on minority groups regarding the mental health impact that COVID-19 and social support trigger. In addition, future studies need to replicate this research in the third-world countries, where mental health is considered a myth or a taboo (Mascayano et al., 2015; Porter et al., 2021). Evidence regarding the power of social support will help people maintain mental wellbeing when health healthcare is not readily available.

Our study explored online and offline social support as separate constructs, not as transferrable entities from online to offline or vice versa. Will the connections made online be strengthened or weakened by the return to face-to-face interactions? Are online relationships sustainable in an offline world? The return to normalcy may also be challenging for those who prefer going to school or working from home. Thus, future research must address how online and offline social support transitions to its opposite and the impacts of such transformations.

\section{DATA AVAILABILITY STATEMENT}

The raw data supporting the conclusions of this article will be made available by the authors, without undue reservation.

\section{ETHICS STATEMENT}

The studies involving human participants were reviewed and approved by UMCIRB 20-002726, Mallory Ball. The patients/participants provided their written informed consent to participate in this study.

\section{AUTHOR CONTRIBUTIONS}

KL conceived the idea of the study and was in charge of data collection. J-AK designed the study and was involved in the analysis and interpretation of data. The manuscript was drafted, reviewed, and approved by both authors.

\section{FUNDING}

This study was conducted with the support of East Carolina University School of Communication. 


\section{REFERENCES}

BBC News (2020, March 31). Coronavirus: Three Out of Four Americans Under Some Form of Lockdown. Available online at: https://www.bbc.com/news/ world-us-canada-52103066

Beaudoin, C. E., and Tao, C. C. (2007). Benefiting from social capital in online support groups: an empirical study of cancer patients. Cyber Psychol. Behav. 10, 587-590. doi: 10.1089/cpb.2007.9986

Berryman, C., Ferguson, C. J., and Negy, C. (2018). Social media use and mental health among young adults. Psychiatric Q. 89, 307-314. doi: 10.1007/s11126-017-9535-6

Bovier, P. A., Chamot, E., and Perneger, T. V. (2004). Perceived stress, internal resources, and social support as determinants of mental health among young adults. Qual. Life Res. 13, 161-170. doi: 10.1023/B:QURE.0000015288.43768.e4

Brailovskaia, J., Ströse, F., Schillack, H., and Margraf, J. (2020). Less Facebook usemore well-being and a healthier lifestyle? An experimental intervention study. Comput. Human Behav. 108, 106332. doi: 10.1016/j.chb.2020.106332

Chen, Y. C., Shang, R. A., and Kao, C. Y. (2009). The effects of information overload on consumers' subjective state towards buying decision in the internet shopping environment. Electron. Commerce Res. Appl. 8, 48-58. doi: 10.1016/j.elerap.2008.09.001

Cobb, S. (1976). Social support as a moderator of life stress. Psychosomatic Med. 38, 300-314. doi: 10.1097/00006842-197609000-00003

Cohen, S., and McKay, G. (1984). "Social support, stress and the buffering hypothesis: a theoretical analysis," in Handbook of Psychology and Health, Vol. IV, Social Psychologycal Aspects of Health, eds A. Baum, S. E. Taylor, and J. E. Singer (Hillsdale, NJ: Routledge), 253-267.

Coyne, S. M., Rogers, A. A., Zurcher, J. D., Stockdale, L., and Booth, M. (2020). Does time spent using social media impact mental health?: an eight year longitudinal study. Comput. Human Behav. 104, 106160. doi: $10.1016 /$ j.chb.2019.106160

Gil de Zúñiga, H., Jung, N., and Valenzuela, S. (2012). Social media use for news and individuals' social capital, civic engagement and political participation. J. Comput. Mediated Commun. 17, 319-336. doi: 10.1111/j.1083-6101.2012.01574.x

Greenberg, N., Docherty, M., Gnanapragasam, S., and Wessely, S. (2020). Managing mental health challenges faced by healthcare workers during covid19 pandemic. Br. Med. J. 368, m1211. doi: 10.1136/bmj.m1211

Haden, S. C., Scarpa, A., Jones, R. T., and Ollendick, T. H. (2007). Posttraumatic stress disorder symptoms and injury: the moderating role of perceived social support and coping for young adults. Personal. Individ. Differ. 42, 1187-1198. doi: 10.1016/j.paid.2006.09.030

Han, X., Han, W., Qu, J., Li, B., and Zhu, Q. (2019). What happens online stays online?-social media dependency, online support behavior and offline effects for LGBT. Comput. Human Behav. 93, 91-98. doi: 10.1016/j.chb.2018.12.011

Henriques, G., and Panizo, M. (2018). "Ch6. The behavioral shutdown model: a consilient biopsychosocial view of depression," in Sociological Theory, Methods, and Perspectives, ed J. H. Michalski (Hauppauge, NY: Nova Science Publishers), 159-188.

House, J. S. (1986). "Social support and the quality and quantity of life," in Research on the Quality of Life, ed F. M. Andrew (Ann Arbor, MI: Survey Research Center; Institute for Social Research; University of Michigan), 253-271.

Keeter, S. (2021). Many Americans Continue to Experience Mental Health Difficulties as Pandemic Enters Second Year. Pew Research Center. Available Online at: https://www.pewresearch.org/fact-tank/2021/03/16/manyamericans-continue-to-experience-mental-health-difficulties-as-pandemicenters-second-year/

Lee, M., and You, M. (2020). Psychological and behavioral responses in South Korea during the early stages of coronavirus disease 2019 (COVID19). Int. J. Environ. Res. Public Health 17, 2977. doi: 10.3390/ijerph170 92977

Leung, L., and Lee, P. S. (2005). Multiple determinants of life quality: the roles of Internet activities, use of new media, social support, and leisure activities. Telematics Informatics 22, 161-180. doi: 10.1016/j.tele.2004.04.003

Lewinsohn, P. M., Seeley, J. R., Roberts, R. E., and Allen, N. B. (1997). Center for Epidemiologic Studies Depression Scale (CES-D) as a screening instrument for depression among community-residing older adults. Psychol. Aging 12, 277-287. doi: 10.1037/0882-7974.12.2.277
Lin, L. Y., Sidani, J. E., Shensa, A., Radovic, A., Miller, E., Colditz, J. B., et al. (2016). Association between social media use and depression among US young adults. Depression Anxiety 33, 323-331. doi: 10.1002/da.22466

Liu, C. H., Stevens, C., Wong, S. H., Yasui, M., and Chen, J. A. (2019). The prevalence and predictors of mental health diagnoses and suicide among US college students: implications for addressing disparities in service use. Depression Anxiety 36, 8-17. doi: 10.1002/da.22830

Liu, H., Liu, W., Yoganathan, V., and Osburg, V. S. (2021). COVID-19 information overload and generation Z's social media discontinuance intention during the pandemic lockdown. Technol. Forecast. Soc. Change 166, 120600. doi: 10.1016/j.techfore.2021.120600

Mascayano, F., Armijo, J. E., and Yang, L. H. (2015). Addressing stigma relating to mental illness in low-and middle-income countries. Front. Psychiatry 6, 38 doi: $10.3389 /$ fpsyt.2015.00038

Mertens, G., Gerritsen, L., Duijndam, S., Salemink, E., and Engelhard, I. M. (2020). Fear of the coronavirus (COVID-19): Predictors in an online study conducted in March 2020. J. Anxiety Disord. 74:102258. doi: 10.1016/j.janxdis.2020.102258

Nace, T. (2020, March 16). Here are the states with the most (and least) coronavirus cases. Forbes. Available online at: https://www.forbes.com/sites/trevornace/ 2020/03/16/here-are-the-states-with-the-most-and-least-coronavirus-cases/? $\mathrm{sh}=545 \mathrm{aa} 44 \mathrm{~d} 6 \mathrm{af} 4$

Naslund, J. A., Aschbrenner, K. A., Marsch, L. A., and Bartels, S. J. (2016). The future of mental health care: peer-to-peer support and social media. Epidemiol. Psychiatric Sci. 25, 113-122. doi: 10.1017/S2045796015001067

National Academy for State Health Policy (2020). States' COVID-19 Public Health Emergency Declaration, Mask Requirements and Travel Advisories. Available online at: https://www.nashp.org/governors-prioritize-health-for-all/

Panchal, N., Kamal, R., Cox, C., and Garfield, R. (2021). The Implications of COVID-19 for Mental Health and Substance Use. Kaiser Family Foundation. Available online at: https://www.kff.org/coronavirus-covid-19/issue-brief/theimplications-of-covid-19-for-mental-health-and-substance-use/

Pasko, K., and Arigo, D. (2021). The roles of social comparison orientation and regulatory focus in college students' responses to fitspiration posts on social media: cross-sectional study. J. Med. Internet Res. Mental Health 8, e26204. doi: $10.2196 / 26204$

Pearlin, L. I., and Schooler, C. (1978). The structure of coping. J. Health Soc. Behav. 19, 2-21. doi: 10.2307/2136319

Perlis, R. H., Green, J., Quintana, A., Gitomer, A., Chwe, H., Simonson, M., et al. (2021). The state of the nation: a 50 state COVID-19 survey report \#23: depression among young adults. The COVID-19 consortium for understanding the public's policy preferences across states 1, 1-9. doi: 10.31219/osf.io/3s8v4

Pfefferbaum, B., and North, C. S. (2020). Mental health and the Covid-19 pandemic. N. Engl. J. Med. 383, 510-512. doi: 10.1056/NEJMp2008017

Porter, C., Favara, M., Hittmeyer, A., Scott, D., Jiménez, A. S., Ellanki, R., et al. (2021). Impact of the COVID-19 pandemic on anxiety and depression symptoms of young people in the global south: evidence from a four-country cohort study. Br. Med. J. Open 11, e049653. doi: 10.1136/bmjopen-2021-049653

Qi, M., Zhou, S. J., Guo, Z. C., Zhang, L. G., Min, H. J., Li, X. M., et al. (2020). The effect of social support on mental health in Chinese adolescents during the outbreak of COVID-19. J. Adolescent Health 67, 514-518. doi: 10.1016/j.jadohealth.2020.07.001

Rossi, R., Socci, V., Talevi, D., Mensi, S., Niolu, C., Pacitti, F., et al. (2020). COVID-19 pandemic and lockdown measures impact on mental health among the general population in Italy. Front. Psychiatry 11, 790. doi: $10.3389 /$ fpsyt.2020.00790

Russo, S., and Amnå, E. (2016). The personality divide: do personality traits differentially predict online political engagement?. Soc. Sci. Comput. Rev. 34, 259-277. doi: 10.1177/0894439315582487

Selkie, E., Adkins, V., Masters, E., Bajpai, A., and Shumer, D. (2020). Transgender adolescents' uses of social media for social support. J. Adolescent Health 66, 275-280. doi: 10.1016/j.jadohealth.2019.08.011

Serafini, G., Parmigiani, B., Amerio, A., Aguglia, A., Sher, L., and Amore, M. (2020). The psychological impact of COVID-19 on the mental health in the general population. QJM Int. J. Med. 113, 531-537. doi: 10.1093/qjmed/hcaa201

Shensa, A., Sidani, J. E., Escobar-Viera, C. G., Switzer, G. E., Primack, B. A., and Choukas-Bradley, S. (2020). Emotional support from social media and faceto-face relationships: associations with depression risk among young adults. $J$. Affect. Disord. 260, 38-44. doi: 10.1016/j.jad.2019.08.092 
Shensa, A., Sidani, J. E., Lin, L., Bowman, N. D., and Primack, B. A. (2016). Social media use and perceived emotional support among US young adults. J. Commun. Health 41, 541-549. doi: 10.1007/s10900-015-0128-8

Sherbourne, C. D., and Stewart, A. L. (1991). The MOS social support survey. Soc. Sci. Med. 32, 705-714. doi: 10.1016/0277-9536(91)90150-B

Vogel, E. A., Rose, J. P., Roberts, L. R., and Eckles, K. (2014). Social comparison, social media, and self-esteem. Psychol. Popular Media Culture 3, 206-222. doi: $10.1037 /$ ppm0000047

Wang, G., Zhang, W., and Zeng, R. (2019). WeChat use intensity and social support: the moderating effect of motivators for WeChat use. Comput. Human Behav. 91, 244-251. doi: 10.1016/j.chb.2018. 10.010

WHO Coronavirus (COVID-19) Dashboard (2021). WHO Coronavirus (COVID19) Dashboard With Vaccination Data. Available online at: https://covid19.who. int

Zhong, B., Huang, Y., and Liu, Q. (2021). Mental health toll from the coronavirus: social media usage reveals Wuhan residents' depression and secondary trauma in the COVID-19 outbreak. Comput. Human Behav. 114, 106524. doi: $10.1016 /$ j.chb.2020.106524
Conflict of Interest: The authors declare that the research was conducted in the absence of any commercial or financial relationships that could be construed as a potential conflict of interest.

Publisher's Note: All claims expressed in this article are solely those of the authors and do not necessarily represent those of their affiliated organizations, or those of the publisher, the editors and the reviewers. Any product that may be evaluated in this article, or claim that may be made by its manufacturer, is not guaranteed or endorsed by the publisher.

Copyright (0) 2022 Longest and Kang. This is an open-access article distributed under the terms of the Creative Commons Attribution License (CC BY). The use, distribution or reproduction in other forums is permitted, provided the original author(s) and the copyright owner(s) are credited and that the original publication in this journal is cited, in accordance with accepted academic practice. No use, distribution or reproduction is permitted which does not comply with these terms. 